\title{
Occupational Rhinoconjunctivitis Induced by Unusual Allergens of Carrot
}

\author{
Sánchez-Guerrero $\mathrm{IM}^{1}$, Nieto $\mathrm{A}^{1}$, Meseguer $\mathrm{J}^{1}$, Navarro $\mathrm{M}^{1}$, López \\ Sáez MP ${ }^{1}$, Magdalena $\mathrm{MK}^{1}$, Sánchez Pérez $\mathrm{M}^{1}$, Pineda $\mathrm{F}^{2}$, López \\ Sánchez JD ${ }^{1}$ \\ ${ }^{1}$ Allergy Service, Hospital Clínico Universitario Virgen de la \\ Arrixaca, Murcia, Spain \\ ${ }^{2}$ Application Laboratory, Diater, Madrid, Spain
}

J Investig Allergol Clin Immunol 2020; Vol. 30(3): 204-206 doi: $10.18176 /$ jiaci.0482

Key words: Carrot allergy. Occupational rhinoconjunctivitis. Immunoblotting. Allergens.

Palabras clave: Alergia a zanahoria. Rinoconjuntivitis ocupacional. Immunoblotting. Alérgenos.

Daucus carota L. (carrot) is a vegetable that belongs to the Umbelliferae (Apiaceae) family. It is frequently implicated in food allergy and oral allergy syndrome, usually in association with other foods. Thus, hypersensitivity to carrot is commonly associated with allergy to Apiaceae species and sensitization to birch and mugwort pollens $[1,2]$. In southern Spain, allergy to Artemisia vulgaris is quite frequent, in contrast to allergy to Betula verrucosa. Nevertheless, few cases of rhinitis and asthma induced by carrot allergy have been reported [3,4]. We investigated the allergens involved in a case of occupational rhinoconjunctivitis induced by carrot.

A 38-year-old male cook diagnosed with allergic rhinitis and asthma due to mite and pollen had been treated successfully with subcutaneous immunotherapy. For the previous 3 years, the patient had developed facial contact urticaria, sneezing, rhinorrhea, and conjunctivitis within a few minutes of handling or cutting raw carrots, although he had previously tolerated both raw and cooked intake.

A skin prick test (SPT) was performed with a set of airborne and commercial food allergens, as well as native fresh foods. The result was positive (average wheal diameter $\geq 3 \mathrm{~mm}$ ) to house dust mite, cat, dog, and pollens (grasses, Salsola, and Olea) and negative to Artemisia species and birch pollens, lipid transfer protein (LTP), profilin, and commercial extract of carrot. Native fresh food SPT was positive to carrot (peel and pulp) and celery and negative to parsley, anise, and dill. A rubbing test with fresh carrot was also negative.

Levels of specific IgE (sIgE) were determined using the ImmunoCap system (Thermo Fisher Scientific). A positive $\operatorname{sIgE}$ result $\left(>0.35 \mathrm{kU}_{\mathrm{A}} / \mathrm{L}\right)$ was recorded for $\mathrm{rPhl} \mathrm{p} 1$ $\left(0.44 \mathrm{kU}_{\mathrm{A}} / \mathrm{L}\right)$, nOle e $1\left(10.10 \mathrm{kU}_{\mathrm{A}} / \mathrm{L}\right)$, nSal k 1 (61.60 kU $\left.\mathrm{A} / \mathrm{L}\right)$, Artemisia vulgaris $\left(10.80 \mathrm{kU}_{\mathrm{A}} / \mathrm{L}\right)$, carrot $\left(12.80 \mathrm{kU}_{\mathrm{A}} / \mathrm{L}\right)$, and celery $\left(12.20 \mathrm{kU}_{\mathrm{A}} / \mathrm{L}\right)$. $\mathrm{sIgE}$ was negative for LTP (rPru p 3) and profilin ( $\mathrm{rPhl} \mathrm{p} \mathrm{12).}$

A causal relationship between exposure to an occupational agent and rhinitis can only be established with certainty by means of specific nasal provocation testing. When this is 
not feasible, the agent can be administered by mimicking the exposure conditions at the workplace under supervision and monitoring the nasal response [5]. As there was no standardized extract for nasal provocation testing, we assessed exposure by having the patient handle the food directly. He had to cut little slices of fresh carrot in a closed room. Ten minutes after initiating exposure, he experienced sneezing, rhinorrhea, nasal obstruction, lacrimation, conjunctival redness, and facial urticaria. The symptoms resolved completely with oral antihistamine in 45 minutes. An open oral challenge test with fresh carrot yielded a negative response.

In order to study the carrot allergens involved in the reaction, protein extracts of carrot (peel and pulp), Artemisia vulgaris, Chenopodium album, Olea europaea, Phleum pratense, and Salsola kali were separated using SDS-PAGE. Binding of IgE antibody to allergens was analyzed using Western blot based on serum from the allergic patient. An antihuman IgE peroxidase conjugate (Dako) and chemiluminescence detection reagents (Western Lightning Chemiluminescence Reagent Plus, Perkin Elmer) were added, following the manufacturer's instructions. IgEimmunoblotting of carrot extract showed bands in the peel and pulp distributed between $17 \mathrm{kDa}$ and $100 \mathrm{kDa}$ (especially in $50-100 \mathrm{kDa}$ ), while 2 intense bands with weights close to $50 \mathrm{kDa}$ and $70 \mathrm{kDa}$ were detected in the peel (Figure, A).

In adults, allergy to vegetables develops mainly as a result of cross-reactivity with allergens from pollens [6,7], that is, the so-called class 2 food allergy, in contrast to class 1 allergy, in which sensitization to allergens takes place through the gastrointestinal tract and can induce allergic reactions as a result of inhaling aerosolized food products in the workplace. Since the patient was sensitized to pollens, a Western blot inhibition test was performed with carrot as the inhibitory phase to investigate the possibility of cross-reactivity with allergens from pollens. The test revealed intermediate inhibition between carrot pulp and carrot peel, with $\operatorname{IgE}$ binding to high-molecular-weight proteins from carrot peel completely abolished. IgE reactivity for raw carrot immunoblot was completely inhibited, whereas no inhibition $(0 \%)$ was found between carrot and pollen allergens (Figure, B and C).

Carrot allergy is generally considered a birch pollenrelated food allergy with Dau c 1 as the major allergen [8]. The patient was not exposed to birch pollen. Moreover, IgE-immunoblotting of carrot extract revealed an apparently genuine series of bands (not Dau c 1, not Dau c 4) in the peel and pulp of carrot; these bands were clearly larger than Dau c 1 (18 kDa). On the other hand, given the high levels of sIgE to celery and Artemisia observed, we considered the possibility of a celery-carrot-birch-Artemisia-spice syndrome caused by an Artemisia pollen allergen weighing from 60 to $70 \mathrm{kDa}$ [9]. However, this possibility was ruled out by the Artemisia immunoblot (Figure, B), which revealed no high-molecular-weight bands, and the fact that the carrot proteins (inhibitory phase) did not inhibit any of the proteins in the Artemisia extract (Figure, C). Sensitization to LTP was also ruled out by the negative results obtained in the SPT and SIgE.

A recent classification of food allergy included class 3 food allergy, in which dust particles and aerosols produced by food processing activities are readily inhaled and can act as primary sensitizers in the airways, causing a distinct form of respiratory food allergy, usually with no symptoms upon ingestion [10]. The characteristics described correspond to those presented by the study patient.

In summary, we demonstrated the presence of carrot allergens in a case of occupational rhinoconjunctivitis without
A

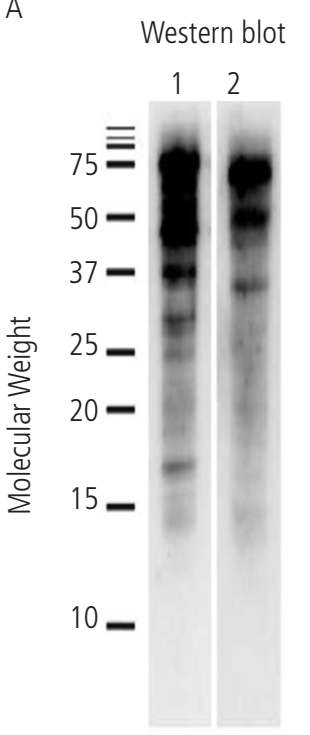

1. Carrot pulp, 2. Carrot peel
B

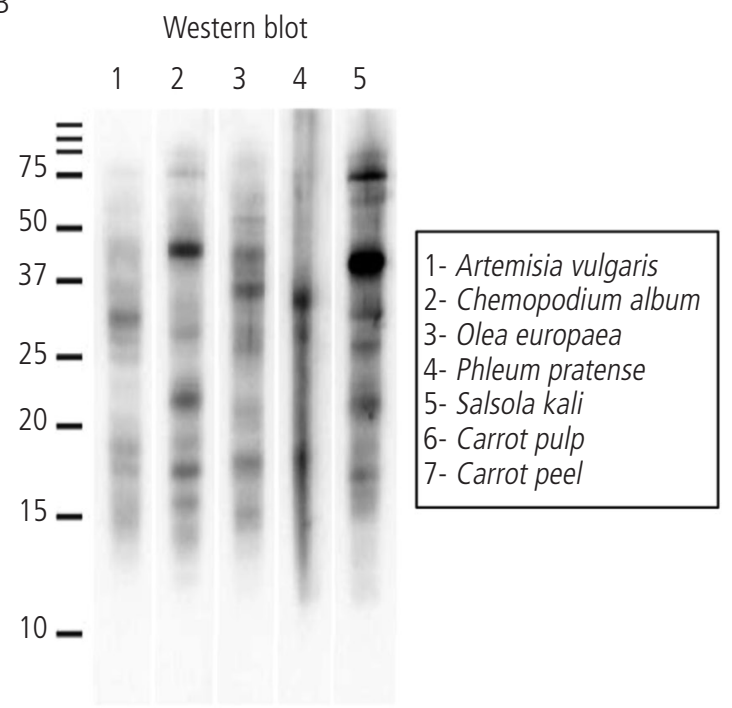

C

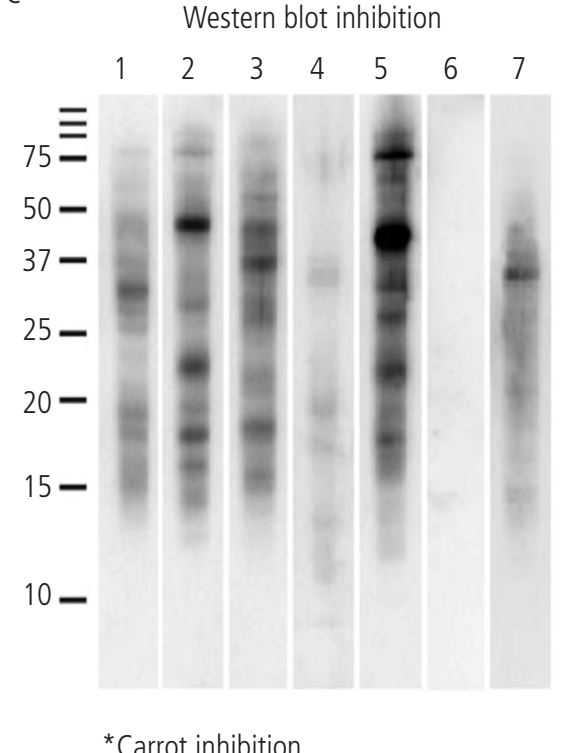

Figure. Immunologic study. A, IgE-immunoblotting of carrot extract (pulp and peel). B, IgE-immunoblotting of pollen extracts. C, Specific IgE Western blot inhibition with carrot as the inhibitory phase. 
food allergy (class 3 food allergy). The positive prick and specific IgE results demonstrated IgE-mediated sensitization to carrot. Moreover, the causal relationship was demonstrated by the positive exposure test result. These data seem to indicate genuine primary sensitization due to unusual airborne allergens that are present in the peel and pulp of carrot and differ from those previously described.

\section{Funding}

The authors declare that no funding was received for the present study.

\section{Conflicts of Interest}

The authors declare that they have no conflicts of interest.

\section{Previous Presentations}

Data from this study were presented in poster form at the 2019 EAACI Congress.

\section{References}

1. Wüthrich B, Stäger J, Johansson SGO. Celery allergy associated with birch and mugwort pollinosis. Allergy. 1990;45:566-71.

2. Bauer $L$, Ebner $C$, Hirschwehr R, Wüthrich B, Pichler C, Fritsch $R$, et al. IgE-cross-reactivity between birch pollen, mugwort pollen and celery is due to at least three distinct crossreacting allergens. Immunoblot investigations of the birchmugwort-celery-syndrome. Clin Exp Allergy. 1996;26:116170.

3. Moreno-Ancillo A, Gil-Adrados AC, Domínguez-Noche C, Cosmes PM, Pineda F. Occupational asthma due to carrot in a cook. Allergol Immunopathol (Madr). 2005;33:288-90.

4. Quirce S, Blanco R, Díez-Gómez M, Cuevas M, Eiras P, Losada E. Carrot-induced asthma: Immunodetection of allergens. J Allergy Clin Immunol. 1997;99:718-9.

5. Hox V, Steelant B, Fokkens W, Nemery B, Hellings PW. Occupational upper airway disease: how work affects the nose. Allergy. 2014;69(3):282-91.

6. Gómez M, Curiel G, Méndez J, Rodríguez M, Moneo I. Hypersensitivity to carrot associated with specific lgE to grass and tree pollens. Allergy. 1996;51:425-9.

7. Scheiner 0 , Aberer $W$, Ebner $C$, Ferreira $F$, HoffmannSommergruber K, Hsieh LS, et al. Cross-reacting allergens in tree pollen and pollen-related food allergy: implications for diagnosis of specific IgE. Int Arch Allergy Immunol. 1997:113:105-8.

8. Moreno-Ancillo A, Gil-Adrados AC, Cosmes PM, DomínguezNoche C, Pineda F. Role of Dau c 1 in three different patterns of carrot-induced asthma. Allergol Immunopathol (Madr). 2006;34:116-20.

9. Lombardero M, García-Sellés FJ, Polo $F$, Jimeno L, Chamorro MJ, García-Casado G, Sánchez-Monge R, et al. Prevalence of sensitization to Artemisia allergens Art v 1, Art v 3 and Art v 60 kDa. Cross-reactivity among Art v 3 and other relevant lipidtransfer protein allergens. Clin Exp Allergy. 2004;34(9):141521.
10. Jeebhay MF, Moscato G, Bang BE, Folletti I, LipińskaOjrzanowska A, Lopata $A L$, et al. Food processing and occupational respiratory allergy-An EAACl position paper. Allergy. 2019;74:1852-71.

- Manuscript received October 8, 2019; accepted for publication January 7,2020

Inmaculada María Sánchez-Guerrero C/Ricardo Gil 26, $2^{\circ} \mathrm{B}$ 30002 Murcia, Spain

E-mail: isanchezguerrero2@gmail.com 